\title{
Spontaneous Intracerebral Hemorrhage (ICH) associated with pregnancy and SARS- CoV-2 infection: a case report
}

\author{
Parisa Dini ${ }^{1}$, Soheila Aminimoghaddam ${ }^{1}$, Zahra Mirzaasgari 2,3 , Neda Rahimian ${ }^{4}$, \\ Samaneh Tanhapour Khotbehsara ${ }^{5}$ and Meysam Abolmaali, ${ }^{2,5^{*}}$ (]
}

\begin{abstract}
Background: Coronavirus Disease 2019 (COVID-19) is predominately known as a respiratory disease associated with pneumonia, acute respiratory distress syndrome and multiorgan failure. However, extra-pulmonary complications of severe acute respiratory syndrome coronavirus 2 (SARS-CoV-2) are increasingly being recognized. In this regard, some studies implied the hemostatic and vascular involvements in patients with SARS-CoV-2 infection.

Case presentation: We describe a case of spontaneous Intracerebral Hemorrhage (ICH) in a pregnant patient with COVID-19 and history of cesarean section a week before the occurrence of $\mathrm{ICH}$. The patient underwent emergent craniotomy with acceptable outcome. Hemorrhagic events, including ICH, may happen during COVID-19 infection with several possible mechanisms.
\end{abstract}

Conclusion: COVID-19 patients, especially high-risk groups, are at a risk of intracranial hemorrhage. Therefore, close follow-up must be maintained and hemorrhagic events must be kept in mind in these cases.

Keywords: COVID-19, Intracerebral hemorrhage, Pregnancy, Case report

\section{Background}

On January 2020, the World Health Organization (WHO) was informed of 44 patients with pneumonia of unknown etiology, by the national authorities of China. These cases later confirmed to be caused by a novel type of coronavirus; which was then named 2019 novel coronavirus (2019-nCoV) and on March 2020, WHO characterized 2019-nCoV outbreak as a pandemic [1, 2]. Soon after the beginning of the pandemic, physicians witnessed several extrapulmonary complications of coronavirus disease 2019 (COVID-19) that were affecting the patients and considered these complications to be the main cause of death. The coagulation system imbalances were

*Correspondence: dr.meysam.a@gmail.com

${ }^{5} \mathrm{School}$ of Medicine, Iran University of Medical Sciences, Tehran, Iran

Full list of author information is available at the end of the article perceived as one of the most important complications of COVID-19 [3, 4]. So far, some studies have implied both thrombotic and hemorrhagic events in the COVID-19 patients [5-7]. Also pregnancy has an effect on hemostasis by causing a hyper-coagulopathy state [8]. It has been seen that pregnant women are more likely to develop severe COVID-19 [9]. However, there were no reports of hemostasis disorders in pregnant women with COVID19. Here we report a case of intracranial hemorrhage in a COVID-19 patient after her childbirth.

\section{Case presentation}

The patient was a 27 years old woman, Gravid3, Para 3, Live 3 (G3P3L3) with no prior history of any disease. She had a repeat Cesarean delivery a week before the symptom onset. The patient was presented to the emergency department, with decreased level of consciousness, 
seizure-like movements and a history of headache. She was infected with COVID-19 (confirmed by nasopharyngeal swab test for SARS-CoV-2 PCR), 2 weeks before the onset of neurological symptoms. She did not receive any anti thrombosis prophylaxis followed by cesarean delivery. On admission, her vital signs were as follows: blood pressure $160 / 90 \mathrm{mmHg}$, heart rate $88 \mathrm{beat} / \mathrm{min}$, respiratory rate 24 breaths/min with oxygen saturation of $92 \%$ on air room and temperature $37.9^{\circ} \mathrm{C}$. Brain $\mathrm{CT}$ scan showed a $30 * 56 \mathrm{~mm}$ hyperdense mass-like lesion in the left fronto-parietal area, with midline shift and mass effect (Fig. 1). Her past medical history, was not consist of abnormal coagulation profile before or after delivery. She had normal coagulable laboratory tests during the admission with normal platelet count, as well. Anticonvulsant therapy (Phenytoin) was commenced and the patient was scheduled for an emergent surgery. Given the history of COVID-19 and ground-glass opacities in the chest CT scan, Remdesivir, Interferon, Cefepime, Dexamethasone and Sofosbuvir were commenced for the patient. She was transferred to the operating room and an urgent evacuation of hematoma via a left fronto-temporo-parietal craniotomy approach was performed. Evacuation of hematoma $(\approx 200 \mathrm{cc})$, drain insertion and duraplasty were performed successfully with no postoperative bleeding. After the surgery, patient was admitted to the intensive care unit. She became extubated a day after surgery. Three days later, a $40^{\circ} \mathrm{C}$ fever started. Therefore, with diagnosis of Hospital acquired pneumonia (HAP), Colistin and Teicoplanin were ordered at this time. The patient became afebrile, but she was aphasic and had right hemiplegia. However, the neurological symptoms of the patient gradually improved within a week. Follow-up brain CT scan was uneventful and the patient was discharged without any serious complications (Fig. 2). On the 2-month follow-up, the patient reported no significant disability. Meanwhile, she refrained to be evaluated by diagnostic cerebral angiography.

\section{Discussion and conclusion}

Since the declaration of COVID-19 pandemic, hundreds of studies have been published from different countries about the characteristics of patients with COVID-19. Among them, some considerable studies have issued the extra-pulmonary complications of SARS-CoV-2 infection [10]. Almost every part of human body can be affected by these complications. Though, hemostasis balance, vessels and central nervous system might be regarded as the most important ones [11]. Occurrence of different types of intracranial hemorrhage in patients with COVID-19 is a known phenomenon and was systematically reviewed by Cheruiyot et al. According to this study, out of 148 individuals with a diagnosis of different intracranial

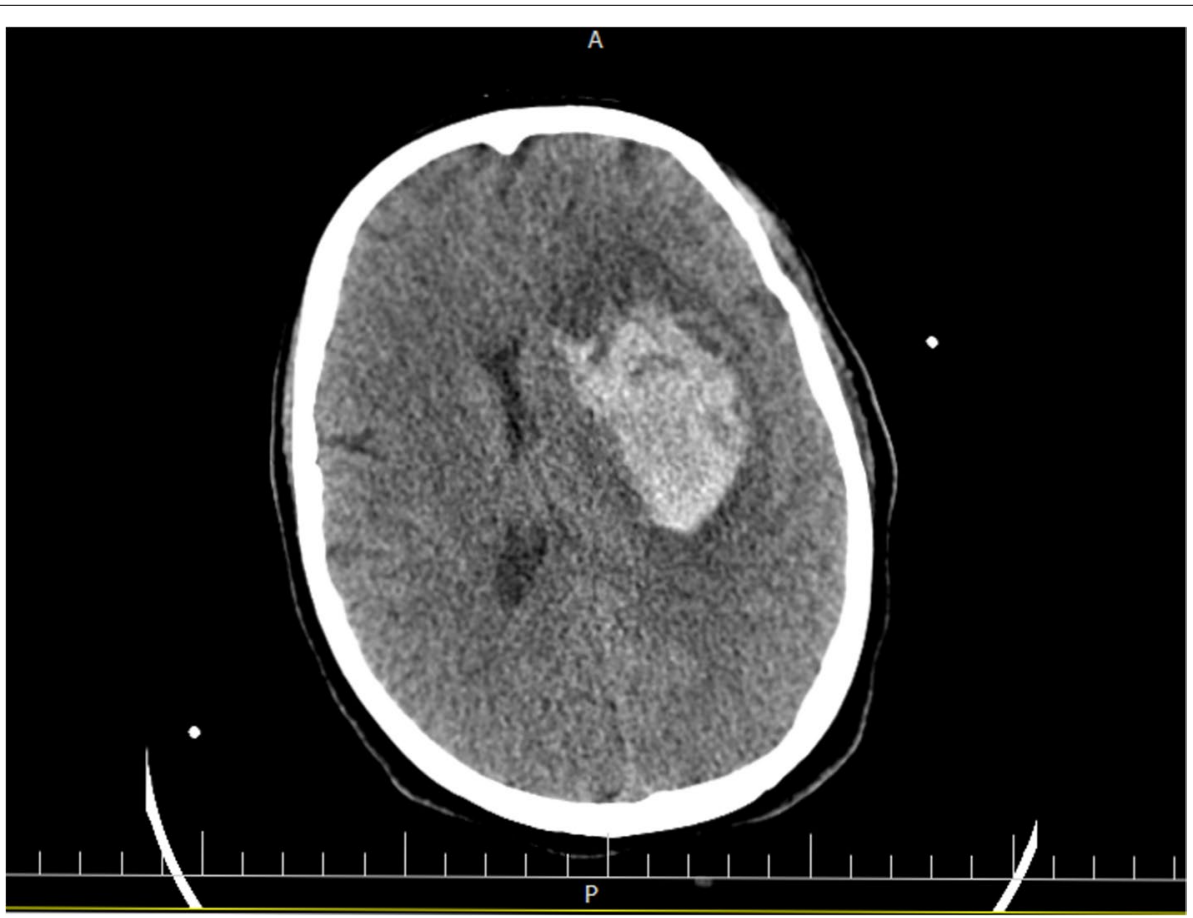

Fig. 1 Axial view of brain CT scan showed a 30*56 mm hyperdense mass-like lesion in the left fronto-parietal area, extensive hemorrhage in left basal ganglia and internal capsule, with midline shift and mass effect 


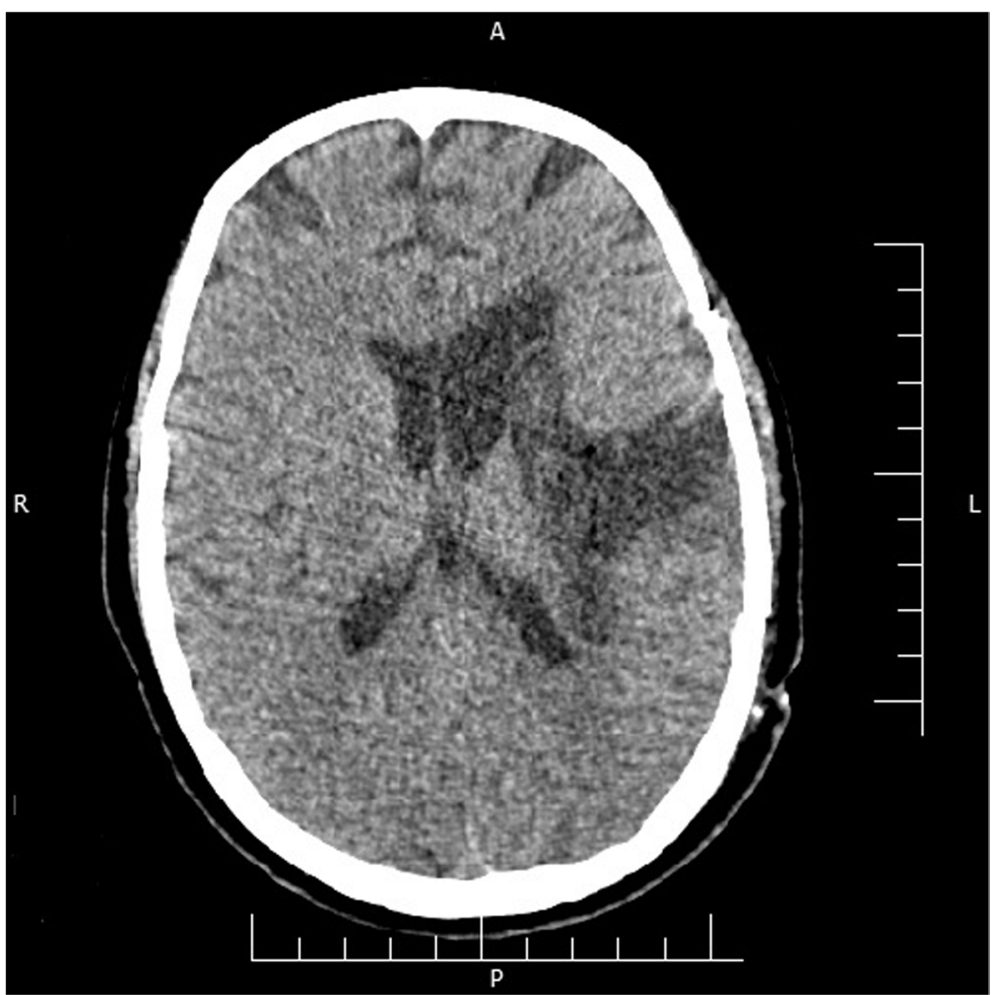

Fig. 2 Brain CT scan showed no signs in favor of rebleeding at the one-week follow-up

hemorrhage, extracted from 23 studies, multiple cranial compartments $(\mathrm{MCH})$ was reported in 14 cases $(9.5 \%)$, intraparenchymal hemorrhage (IPH) was reported in 93 (62.6\%), subarachnoid hemorrhage (SAH) in $22(15.0 \%)$, subdural hemorrhage (SDH) in 17 (11.6\%), and isolated intraventricular hemorrhage $(\mathrm{IVH})$ were reported in only 2 cases [12]. To the best of our knowledge, occurrence of intracranial hemorrhage in a pregnant woman infected with COVID-19 have not been reported so far.

In addition to the increased risk of spontaneous ICH in patients with COVID-19, pregnancy itself can be considered as a risk factor for nontraumatic $\mathrm{ICH}$. about which, Meeks et al. demonstrated an increased rate of $\mathrm{ICH}$ during the third trimester and the first 12 postpartum weeks [13]. Data from previous studies demonstrated an increase in the risk of $\mathrm{ICH}$ in pregnant women with eclampsia, gestational hypertension, coagulopathy, and history of tobacco use by increasing the states of cerebral hyper-perfusion [13]. However, we observed none of these factors in this case. Given the above findings, pregnant women with SARS-CoV-2 infections might be at a higher risk for spontaneous $\mathrm{ICH}$. Therefore, physicians must be aware of hemorrhagic complications at the time of COVID-19 pandemic. Especially, in pregnant individuals suspicious of COVID-19 infection.
In conclusion, pregnant women infected with COVID-19 seem to be more prone to develop ICH. Therefore, any symptoms pertaining to the central nervous system must be assessed for possible kinds of intracranial hemorrhage. The concurrence of the postpartum period and COVID-19 may be one of the causes of cerebral hemorrhage in this patient. However, the causation is not certain and suggested to investigate the possibility of causality or coincidence in further studies.

\section{Abbreviations}

COVID-19: Coronavirus Disease 2019; SARS-CoV-2: Respiratory syndrome coronavirus 2; ICH: Intracerebral Hemorrhage; WHO: World Health Organization; 2019-nCoV: 2019 novel coronavirus; HAP: Hospital acquired pneumonia; MCH: Multiple cranial compartments; IPH: Intraparenchymal hemorrhage; SAH: Subarachnoid hemorrhage; SDH: Subdural hemorrhage; IVH: Intraventricular hemorrhage.

\section{Acknowledgements}

Not applicable.

\section{Authors' contributions}

All authors have read and approved the manuscript. PD: Involved in patient management, collected history and revised the manuscript. ZM: Reviewed results and revised the manuscript. NR: Did background research. ST: Drafted, did background research. SA: Involved in patient management. MA: Drafted, did background research, reviewed results and revised the manuscript. 


\section{Funding}

The authors received no financial support for the research, authorship, and/or publication of this article.

\section{Availability of data and materials}

Not applicable.

\section{Declarations}

\section{Ethics approval and consent to participate}

This study was conducted in accordance with the declaration of Helsinki.

\section{Consent for publication}

Written informed consent was obtained from the patient for publication of this Case report and any accompanying images. A copy of the written consent is available for review by the Editor of this journal.

\section{Competing interests}

The authors declare no conflict of interest.

\section{Author details}

${ }^{1}$ Department of Gynecology, Firoozgar Hospital, Iran University of Medical Sciences, Tehran, Iran. ${ }^{2}$ Shefa Neuroscience Research Center, Khatam Alanbia Hospital, Tehran, Iran. ${ }^{3}$ Department of Neurology, Firoozgar Hospital, Iran University of Medical Sciences, Tehran, Iran. ${ }^{4}$ Department of Internal Medicine, Firoozgar Hospital, Iran University of Medical Sciences, Tehran, Iran. ${ }^{5}$ School of Medicine, Iran University of Medical Sciences, Tehran, Iran.

Received: 28 July 2021 Accepted: 16 December 2021

Published online: 06 January 2022

\section{References}

1. Organization WH. Novel coronavirus (2019-nCoV) situation report 1. 2020

2. Organization WH. Coronavirus disease 2019 (COVID-19): situation report, 82. 2020.

3. Huang C, Wang Y, Li X, Ren L, Zhao J, Hu Y, et al. Clinical features of patients infected with 2019 novel coronavirus in Wuhan, China. Lancet. 2020:395(10223):497-506.

4. Chen N, Zhou M, Dong X, Qu J, Gong F, Han Y, et al. Epidemiological and clinical characteristics of 99 cases of 2019 novel coronavirus pneumonia in Wuhan, China: a descriptive study. Lancet. 2020;395(10223):507-13.

5. Mongula J, Frenken M, Van Lijnschoten G, Arents N, de Wit-Zuurendonk L, Schimmel-de Kok A, et al. COVID-19 during pregnancy: non-reassuring fetal heart rate, placental pathology and coagulopathy. Ultrasound Obstet Gynecol. 2020;56(5):773-6.

6. Kinsey KE, Ganz E, Khalil S, Brustman L. Intraoperative coagulopathy during cesarean section as an unsuspected initial presentation of COVID-19: a case report. BMC Pregnancy Childbirth. 2020;20(1):1-3.

7. Takayama W, Endo A, Yoshii J, Arai H, Oi K, Nagaoka E, et al. Severe COVID19 pneumonia in a 30-year-old woman in the 36th week of pregnancy treated with postpartum extracorporeal membrane oxygenation. Am J Case Rep. 2020;21:e927521.

8. Soma-Pillay P, Catherine N-P, Tolppanen H, Mebazaa A, Tolppanen $\mathrm{H}$, Mebazaa A. Physiological changes in pregnancy. Cardiovasc J Afr. 2016;27(2):89.

9. Ko JY, DeSisto CL, Simeone RM, Ellington S, Galang RR, Oduyebo T, et al. Adverse pregnancy outcomes, maternal complications, and severe illness among US delivery hospitalizations with and without a coronavirus disease 2019 (COVID-19) diagnosis. Clin Infect Dis. 2021;73(Suppl 1):S24-s31.

10. Mottaghi A, Roham M, Makiani MJ, Ranjbar M, Laali A, Rahimian NR. Verifying extra-pulmonary manifestation of COVID-19 in Firoozgar hospital 2020: an observational study; 2021.

11. Di Minno MND, Calcaterra I, Lupoli R, Storino A, Spedicato GA, Maniscalco $M$, et al. Hemostatic changes in patients with COVID-19: a meta-analysis with meta-regressions. J Clin Med. 2020;9(7):2244.

12. Cheruiyot I, Sehmi P, Ominde B, Bundi P, Mislani M, Ngure B, et al. Intracranial hemorrhage in coronavirus disease 2019 (COVID-19) patients. Neurol Sci. 2020:42:1-9.
13. Meeks JR, Bambhroliya AB, Alex KM, Sheth SA, Savitz SI, Miller EC, et al. Association of primary intracerebral hemorrhage with pregnancy and the postpartum period. JAMA Netw Open. 2020;3(4):e202769.

\section{Publisher's Note}

Springer Nature remains neutral with regard to jurisdictional claims in published maps and institutional affiliations.
Ready to submit your research? Choose BMC and benefit from

- fast, convenient online submission

- thorough peer review by experienced researchers in your field

- rapid publication on acceptance

- support for research data, including large and complex data types

- gold Open Access which fosters wider collaboration and increased citations

- maximum visibility for your research: over 100M website views per year

At BMC, research is always in progress.

Learn more biomedcentral.com/submissions 